\title{
Ambiente do Centro Cirúrgico e os elementos que o integram: implicações para os cuidados de enfermagem
}

\author{
Surgical Center environment and its elements: implications for nursing care
}

Ambiente del Quirófano y sus elementos: implicaciones para la atención de enfermería

\author{
Denise Conceição Silva', Neide Aparecida Titonelli Alvim' \\ 'Universidade Federal do Rio de Janeiro. Escola de Enfermagem Anna Nery. \\ Núcleo de Pesquisa de Fundamentos do Cuidado de Enfermagem. Rio de Janeiro, RJ
}

Submissão: 26/09/2009

Aprovação: 20/03/2010

\section{RESUMO}

Pesquisa Qualitativa Que objetivou caracterizar os elementos que integram o ambiente do Centro Cirúrgico e analisar suas implicações para a dinâmica de cuidar e de cuidados de enfermagem. Ancorou-se nos princípios da Teoria Ambientalista. Participaram 12 enfermeiras do centro cirúrgico de um Hospital Universitário do Rio de Janeiro. Os dados foram produzidos pela técnica de criatividade e sensibilidade "Mapa-Falante", entrevista semi-estruturada e observação participante; e analisados por categorias temáticas. Os resultados apontam Que o cuidado ocorre direta e indiretamente, em prol da plena restauração do cliente, incluindo o ambiente Que o integra, de modo a manter-se harmônico e ęuilibrado. As intervenções da enfermeira são no sentido de manter o ambiente em condições favoráveis de modo a torná-lo promotor de cuidados.

Descritores: Ambiente; Cuidados de enfermagem; Enfermagem de centro cirúrgico.

\section{ABSTRACT}

The purpose of this Qualitative research was to characterize the elements that constitute the environment of the Surgical Center and to analyze its implications for dynamic of care and nursing care. Based on the Environmental Theory's principals. Participated twelve nurses from the Surgical Center of a College Hospital in Rio de Janeiro. Data were gathered through the creativity and sensitivity technique "Map-Speaker", semi-structered interviews and participant observation, and were analyzed by thematic categories. The results showed that care can happen directly and indirectly in favor of full client recovery, counting the environment that the integrate in purpose to maintain harmonic and balanced. The nurse interventions aim to maintain the environment in favorable conditions so that a higher standard of care can be promoted.

Key words: Environment; Nursing care; Operating room nursing.

\section{RESUMEN}

Investigación cualitativa Que objetivó caracterizar los elementos Que integran el ambiente del Quirófano y analizar sus implicaciones para la dinamica del cuidar y del cuidado de enfermería. Basada en los principios de la Teoría Ambientalista. Participaran 12 enfermeras del Quirófano de un Hospital Universitario del Río de Janeiro. Los datos foran producidos por la técnica de creatividad y sensibilidad "Mapa-Hablante", entrevista semi estructurada y observación participante; y analizados por categorías temáticas. Los resultados apuntan Que el cuidado ocurre directa e indirectamente, a favor de la plena restauración del cliente, incluyendo el ambiente que lo integra, de modo a mantenerse harmónico y eQuilibrado. Las intervenciones de la enfermera son en el sentido de mantener el ambiente en condiciones favorables de modo a tornalo promotor de los cuidados.

Descriptores: Ambiente; Atención de enfermería; Enfermería de Quirófano. 


\section{INTRODUÇÃO}

Na especificidade do centro cirúrgico, a dinâmica do cuidar e os cuidados de enfermagem são muito voltados à objetividade das ações, cuja intervenção é de natureza técnica, visando à recuperação do cliente. Dadas as características do setor, a interação social no cuidado muitas vezes é restrita. A presença da enfermeira junto ao leito, a demonstração de afeto, o toQue, a conversa também são restritos face às atividades outras do setor, o Que não Quer dizer Que não haja expressividade no cuidado. Isto acontece, por vezes, não no sentido de desmerecer ou desvalorizar os aspectos do cuidar Que são da ordem da subjetividade, mas porque, neste setor, a atenção ao órgão físico como central é necessária. O pouco tempo de convivência com o cliente no centro cirúrgico embora não seja o determinante, pode também interferir na construção da relação entre ele e a enfermeira.

Uma situação freQuente na estrutura organizacional da instituição hospitalar em geral é o Quantitativo dos profissionais de enfermagem, geralmente em número insuficiente em relação à demanda das necessidades de um processo de cuidar holístico e humanizado. Por um lado, este aspecto pode resultar em uma priorização das atividades gerenciais e dos cuidados instrumentais em relação aos do tipo expressivo, determinante para a construção de uma base sustentadora no cuidado junto ao cliente. Por outro lado, acaba também por afetar o ambiente psicológico dos profissionais Que se sentem pressionados e assoberbados com suas inúmeras atribuições, acrescidas da escassez de recursos materiais no desenvolvimento de suas ações, prejudicando, por vezes, o diálogo, a troca de informações e experiências, e o desenvolvimento de um trabalho harmônico e solidário, fragilizando as relações estabelecidas entre eles ${ }^{(1-2)}$.

Mesmo Quando não se encontra presente no cuidado direto a enfermeira presta cuidados indiretos ao cliente, no planejamento e na delegação de ações, na previsão e provisão de recursos, na capacitação de sua equipe, visando sempre à concretização e melhorias no cuidado. Portanto, ela toma as devidas providências para Que os profissionais possam exercer suas funções do modo mais eficiente possível, criando um ambiente favorável ao desenvolvimento de seu trabalho, propiciando, assim, a Qualidade da assistência Que os clientes necessitam. Deste modo, esta profissional congrega uma série de ações Que no seu conjunto visam proporcionar a restauração plena do cliente ${ }^{(3)}$.

Compartilhamos dessa concepção de cuidado imbuído da interação com o meio ambiente entendido como orgânico. Ademais, vale dizer Que o cuidado nessa visão inclui, também, a integração entre os profissionais e destes com os clientes. Ou seja, um cuidado em Que se considera além dos aspectos ligados ao corpo biológico, e os interativos, com o ambiente físico e social maior, aquele Que se evidencia no intrapessoal, valorizando a expectativa e o desejo do outro no processo de cuidar.

Ocorre que, dada a dinâmica e a finalidade mesma do setor Que ora nos ocupamos em discutir muito centrada na intervenção corretiva; além de a natureza rotativa da clientela neste setor associada à dificuldade da presença efetiva da enfermeira junto ao cliente neste espaço, os cuidados de enfermagem Que não se expressam no procedimento técnico e no emprego de tecnologias de ponta acabam não tendo, por vezes, a devida visibilidade, ainda Que todas as ações realizadas pela enfermeira tenham como foco de interesse e preocupação, o cuidado ao cliente no intento de sua restauração plena. Essas ações se voltam ao ambiente em Que o cuidado ocorre. No seu bojo estão situados, além dos sujeitos envolvidos no processo de cuidar, fatores Que permeiam e implicam em todo esse processo(l).

Se, por um lado, é essencial o cuidado que se constrói no encontro entre sujeitos, no caso, da enfermeira com o cliente, por outro lado, ainda Que nem sempre o cuidado por ela desenvolvido se construa na relação face a face com o cliente, há uma série de ações realizadas pela enfermeira Que caracterizam sua pré-ocupação com ele, logo, com o cuidado a este, garantindo-lhe conforto e bem-estar. Daí a importância de dissertar sobre os elementos Que integram o ambiente do centro cirúrgico e suas implicações para a dinâmica de cuidar e para os cuidados de enfermagem, sendo este o objeto do presente estudo. Os objetivos foram: caracterizar os elementos que integram o ambiente do Centro Cirúrgico; e analisar as implicações desses elementos para a dinâmica de cuidar e para os cuidados de enfermagem.

\section{BASE TEÓRICA}

O estudo se ancorou nos princípios da Teoria Ambientalista ${ }^{(4)}$. Esta teoria concebe o ambiente em todos os seus aspectos - físico, psicológico e social, uma vez Que estes interferem diretamente no conforto e bem-estar das pessoas, influenciando na manutenção ou na restauração de sua energia vital. Destaca Que Quando um ou mais aspectos do ambiente encontra-se deseQuilibrado, o cliente deve usar maior energia para contrabalançar o estresse ambiental, o Que retira de si a energia necessária para a cura. Nesse sentido, a ação da Enfermagem é fundamental na organização e manutenção do ambiente, cabendo aos seus profissionais nele intervir, "tudo com um mínimo de dispêndio da capacidade vital do paciente" ${ }^{(4)}$. Dessa forma, ele não usa sua energia disponível para adaptar-se ao ambiente, mas sim, a utiliza para sua recuperação. Segundo esta teoria ${ }^{4}$, o papel da enfermeira é o de colocar o cliente na melhor posição para Que a natureza possa agir sobre ele. Portanto, as intervenções desta profissional devem se assentar no equilíbrio do ambiente para Que o cliente canalize todas as suas energias a favor de sua recuperação.

Embora haja uma ênfase sobre o ambiente físico, na atenção à ventilação, iluminação, limpeza, aspectos estes Que, Quando adequados, são capazes de manter o organismo em condições favoráveis para o restabelecimento da saúde do cliente, as preocupações da teoria ambientalista também incluem os aspectos psicológicos, referentes aos relacionamentos estabelecidos entre profissionais e clientes, além dos profissionais entre si; e sociais desse ambiente, relacionados ao ambiente total do cliente, isto é, para além do espaço hospitalar. Inclui as suas condições de vida e de visão de mundo Que interferem no seu processo saúde-doença. Deste modo, esta teoria nos apóia na discussão sobre como intervir no ambiente do centro cirúrgico - físico, social e o de relações interpessoais, de modo a torná-lo promotor de saúde/cuidados.

\section{MÉTODO}

Estudo Qualitativo, realizado em um hospital universitário geral, de grande porte, situado na cidade do Rio de Janeiro. Os sujeitos foram 12 enfermeiras atuantes no centro cirúrgico. Utilizou-se a 
entrevista semi-estruturada conjugada à técnica de criatividade $\mathrm{e}$ sensibilidade (TCS) denominada "Mapa-Falante"(5), além da observação participante na produção dos dados. Essa técnica consistiu na construção individual de um mapa geográfico do cenário estudado por cada sujeito, a partir da seguinte temática: "Fale sobre a sua atuação no Centro Cirúrgico". Os dados foram analisados com base na análise de conteúdo temática ${ }^{(6)}$. $\mathrm{O}$ estudo atendeu aos princípios da Resolução 196/96, tendo sido aprovado pelo Comitê de Ética em Pesquisa do referido hospital (Protocolo $n^{\circ}$ 209/08). Da análise de conteúdo temática emergiram as categorias: I) Características físico-estruturais e de funcionalidade do centro cirúrgico do HUCFF. Subcategorias: A presença de ruídos e outros componentes físicos; Dificuldades materiais e de recursos humanos. 2) O ambiente psicológico e social do centro cirúrgico. Subcategorias: Aspectos implicados nas relações entre clientes e enfermeiras; Relações entre os profissionais de saúde.

\section{RESULTADOS E DISCUSSÃO}

\section{Características físico-estruturais e de funcionalidade do cenário do estudo}

O centro cirúrgico do Hospital Universitário, dotado de 2 I salas de cirurgia, atende à legislação Que trata de sua funcionalidade ${ }^{(7)}$. Seu formato retangular é o recomendado uma vez Que proporciona uma funcionalidade das áreas Que compõem a unidade, permitindo a observação constante dos pacientes:

Eu coloquei só Quatro (salas de cirurgia) aqui (referindo-se ao seu mapa falante) pra indicar Que elas todas de um mesmo lado do Centro Cirúrgico. (...) A importância dessas salas de ficarem ali é porque do outro lado, a gente vai ter as salas de apoio, que são salas que ajudam em determinadas situações de que a gente precisa pra resolver dentro do centro cirúrgico. Essas salas de apoio, eu botei como exemplo, o raio- $X$, o laboratório, a sala de vídeo, o expurgo, a patologia, e tem outras, tá?! Mas, fiz um exemplo assim [referindo-se ao seu mapa falante] pra você entender o porQuê que essas salas são importante (E8).

Existem três zonas que compõem o centro cirúrgico: irrestrita (proteção), semi-restrita (limpa) e restrita (estéril) ${ }^{(8-9)}$. A entrada no setor só é permitida a pessoas devidamente identificadas e a circulação em seu interior é feita mediante o uso de roupas específicas para esta unidade. Existem algumas normas que devem ser cumpridas como, por exemplo, lavagem das mãos para a prevenção de infecções hospitalares, devendo ser realizada antes e após o contato direto com o cliente. O setor possui uma dinâmica física e de funcionamento bem peculiar:

Ao chegar, né? Aí, vai adentrando ao centro cirúrgico. É... Pegamos a roupa pra entrar. Percorremos um corredor. Vamos até $o$ vestiário... No caso, onde a gente troca de roupa. Do vestiário a gente sai e entra direto no corredor do Centro Cirúrgico onde estão todas as salas. E, nesse corredor, nós encontramos a sala de Anatomia Patológica, a sala da Chefia de Enfermagem, o expurgo... Temos, também, a RPA nesse corredor. Temos a sala do Ecônomo, o almoxarifado central do Centro Cirúrgico, a sala de Raio-X. A sala da anestesia. $O$ almoxarife da anestesia. A sala de vídeo. Mais... As salas [de cirurgia] também. E, cada sala é acompanhada do seu apoio, né?! O seu apoio e seu lavabo. (E2)

O Posto de Enfermagem localiza-se no centro da unidade, entre os setores de Recepção Pré-Operatória (RPO) e de Recuperação Pós-Anestésica (RPA), destinando-se ao controle administrativo (planta física em anexo). Possui disposição em "U", com acesso, tanto à parte externa, Quanto à parte interna do centro cirúrgico, o Que permite Que a enfermeira veja o Quê ocorre em ambos os setores:

É o coração do centro cirúrgico! Porque é onde a gente recebe os pacientes do andar [setor de internação] e, de lá, depois da recuperação pós-anestésica, a gente o devolve pro andar ou pro CTI, dependendo do tipo de intervenção Que foi feita. (E7)

Possui uma pia para a lavagem das mãos, uma bancada destinada ao preparo de medicamentos, um carrinho para atendimento em caso de parada cárdio-respiratória e dois computadores. Encontrase ainda o estoque de materiais e medicamentos das alas de RPO e RPA. A RPO é composta por cerca de sete macas (depende do número de cirurgias por dia) e cadeiras para acompanhantes (crianças e idosos); e a RPA por dez leitos. Macas e leitos encontramse agrupados, um ao lado do outro. Via de regra as enfermeiras Que atuam no posto de enfermagem são as mesmas Que recepcionam o cliente tanto na RPO, Quanto na RPA. Na verdade, elas identificam tanto o posto de enfermagem, Quanto a RPO e a RPA como um único grande setor:

Primeiro eu recebo o paciente na RPO e depois na RPA. Eu recebo os pacientes do pré-operatório e depois no pósanestésico. Eu recebo aqui, ó lapontando para o seu Mapa Falante]. Quando eu recebo os pacientes daQui (enfermarias), eles vêm para a sala... de operação... (E3)

$\mathrm{Na}$ RPA, as enfermeiras recebem os clientes Que saíram da cirurgia e Que estão se recuperando da anestesia, visando o seu restabelecimento hemodinâmico. Trata-se de um local central onde circulam as informações de diferentes naturezas:

Botei um monte de bonequinhos aqui [apontando para o seu Mapa Falante] circulando pra lá e pra cá. PorQue a gente trabalha com muita gente, entendeu? Um fluxo bastante grande de pessoal. (...)É um ponto central do Centro Cirúrgico. Tem dois degraus, né? Ele fica mais alto, elevado. Você tem uma visão melhor dos pacientes. É um lugar que a gente fica sabendo, assim, de todas, Quase todas as informações. Quem chega dá informação, pede informação. E, ali é onde a gente solicita uma série de coisas. (E9)

As enfermeiras responsáveis pelas salas de cirurgia circulam de umas às outras, para supervisionar os demais profissionais de enfermagem, realizar procedimento privativo, tomar conhecimento da demanda de determinada sala, material ou de pessoal, atendendo às solicitações necessárias ao prosseguimento das cirurgias. A disposição física do corredor e das salas de operação do centro cirúrgico foi apontada pelas enfermeiras participantes da pesQuisa 
como um dos fatores Que dificultam a sua atuação, em especial no cuidado prestado no setor, principalmente para as enfermeiras responsáveis pelas salas de operação (SO), Que precisam se locomover de uma sala para outra durante o seu plantão:

(...) Eu acho que a distribuição de sala deles aqui é péssima. Eu acho isso aQui péssimo [aponta as distâncias entre as salas desenhadas em seu mapa falante]. (...) Isso aqui eu acho Que tem Quase 50 anos, Que acredito terem feito nessa estrutura. Eles poderiam ter feito uma [sala] de frente pra outra. Né?! (...) Se o corredor fosse mais centralizado, o serviço seria bem melhor. Até pra Questão de saúde da gente também. (...) A distância entre as salas é muito difícil. (E2)

O fator que prejudica muito a gente aqui é o espaço físico. Eu Quando estou no corredor [SO]... As pernas se acabam. (...) $O$ espaço físico aQui arrebenta muito com a gente. Quando eu estou na RPA a cabeça se acaba. AQui [referindo-se a SO ilustrada em seu mapa falante] você tem pernas. Aqui [RPA], cabeça. (E3)

Denota-se da fala de E3 Que, na RPA, a enfermeira tem um desgaste psicológico, pois é um setor Que necessita de um profissional Que consiga atender às diferentes demandas de cuidados. Já na SO há um desgaste físico, devido ao distanciamento geográfico entre as salas. Ressalta-se Que ambos os tipos de desgaste sofrido pela enfermeira podem interferir ou influenciar na Qualidade do cuidado prestado ${ }^{(1)}$.

\section{A presença de ruídos e outros componentes físicos}

A enfermeira deve estar atenta à promoção de um ambiente traneüilo, livre de ruídos, tumultos e conversas paralelas. Afinal, embora as atividades de enfermagem de natureza instrumental sejam, por vezes, de maior visibilidade, como administração de medicamentos, curativos, cateterismo e outros procedimentos técnico-invasivos, esta profissional é responsável pela ambientação do cliente no espaço hospitalar, objetivando a restauração da saúde desse indivíduo ${ }^{(10)}$.

Sobre a influência do ambiente físico, na promoção de bemestar e conforto do cliente, várias situações nos chamaram a atenção durante a observação participante realizada. A que mais nos causou espécie e até um certo constrangimento foi o excesso de ruídos a Que constantemente os clientes são submetidos, como o toque contundente e em alto som do celular dos profissionais Que ali atuam e do telefone fixo do posto de enfermagem; além das frequentes conversas de diferentes conteúdos entre os profissionais, muitas vezes, não referentes à situação mesma Que envolve o cliente.

É necessário assegurar um ambiente livre de sons desagradáveis e conversas paralelas "pois nem o melhor arejamento possível, nenhuma assistência, por mais cuidadosa, poderá fazer bem a esses pacientes sem o necessário silêncio"(4). Por um lado, isso denota a preocupação da enfermeira com o conforto do cliente; por outro lado, contribui com a sua observação acurada no sentido de manterse atenta a QualQuer som proveniente do cliente ou de aparelhos a ele conectados Que permita a profissional identificar possíveis alterações no estado de saúde do cliente.

A iluminação do corredor central do setor é do tipo artificial, com lâmpadas fluorescentes e incandescentes a fim de permitir uma observação mais precisa da presença de palidez e cianose nos clientes; enquanto Que a do corredor transversal possui também iluminação do tipo natural, proveniente das janelas existentes ao longo dessa área Que devem permanecer fechadas para a garantia de esterilização( ${ }^{(1)}$. Ao final deste corredor encontram-se o serviço de esterilização e uma área de lazer para funcionários.

Ainda sobre o ambiente físico, destaca-se a constante submissão às baixas temperaturas advindas da ventilação artificial necessária à manutenção do ambiente asséptico. Neste caso, deve-se manter o cliente sempre aQuecido. O sistema de refrigeração através de ar condicionado visa remover gases anestésicos e partículas em suspensão, controlar a temperatura e a umidade, promover troca de ar adequada e evitar a entrada de partículas de áreas subjacentes ${ }^{(12)}$. O controle da temperatura e umidade do ar deve ser feito somente pelo serviço de manutenção do centro cirúrgico. A atenção à temperatura confortável deve estar voltada tanto para as equipes multiprofissionais, Quanto para o cliente.

Quanto às cores neutras, suaves e foscas das paredes do centro cirúrgico, estas são para evitar a emissão de reflexos luminosos, a fadiga visual, o cansaço e os estímulos nervosos ${ }^{(7)}$. Além dos cuidados relativos à ventilação, ao controle dos excessos de ruídos, à manutenção da temperatura corporal do cliente, e às cores adeQuadas das paredes do setor, destaca-se também a necessária manutenção do espaço físico livre de sujidades e de odores desagradáveis ${ }^{(4)}$.

\section{Dificuldades materiais e de recursos humanos}

A precariedade de recursos materiais foi apontada pelas enfermeiras como um fator Que dificulta sua atuação no Centro Cirúrgico e que resulta, por vezes, em suspensão do ato cirúrgico Quando não há material necessário e em Quantidade suficiente para a realização de um determinado procedimento:

\section{A gente não consegue desenvolver um bom trabalho, porQue} falta material. Falta eQuipamento. (E9)

Por mais que a gente Queira que o Centro Cirúrgico funcione com a capacidade Que ele tem pra funcionar, a gente não está conseguindo isso, justamente porque falta material. (...) Então, isso acaba dificultando o nosso trabalho. (E I)

A enfermeira precisa garantir um ambiente propício para o desenvolvimento do cuidado, envolvendo, dentre outros, o meio ambiente físico e social. No entanto, apesar de esta profissional preocupar-se com a manutenção desses recursos de modo a manter o ambiente seguro e de Qualidade na promoção do cuidado ao cliente, o seu desempenho em prover a unidade com esses insumos nem sempre é o suficiente para mantê-la em pleno funcionamento ${ }^{(2-13)}$.

Vários são os aspectos do ambiente físico Que estão implicados nos cuidados de enfermagem ao cliente submetido a um ato cirúrgico e que devem ser considerados pela enfermeira. Cabe a ela conhecer os requisitos mínimos para manter este ambiente adequado tanto para a realização do procedimento anestésico-cirúrgico em si, tornando viável a atuação da equipe cirúrgica nessa unidade, Quanto para os cuidados necessários à promoção do conforto e bem-estar do cliente. Para tanto, ela precisa conhecer a legislação específica vigente a fim de implementar uma assistência adequada ao cliente, promovendo um ambiente seguro para este e para os profissionais atuantes no setor $^{(9)}$. 
Não devamos nos esquecer, entretanto, Que se, o cuidado se estabelece na relação entre sujeitos e Que ambos importam no cuidado, os profissionais também devem ser foco de preocupação da enfermeira, no sentido de atendimento de suas demandas psicológicas, físicas e sociais: o fator emocional do cliente e suas vivências prévias de cirurgia ou hospitalização, a experiência e a satisfação dos profissionais no trabalho, o Quantitativo de recursos humanos e materiais, bem como a Qualidade das relações interpessoais. Esses aspectos estão intrinsicamente relacionados e implicam na dinâmica de cuidar e nos cuidados de enfermagem, desenvolvidos no centro cirúrgico.

\section{O ambiente psicológico e social do centro cirúrgico}

Estudos atuais ${ }^{(14-15)}$ vêm apontando a importância de um ambiente humanizado Que inclui uma assistência também humanizada, em Que se busque não somente o bem-estar do cliente, mas também dos profissionais de saúde Que nele atuam. Portanto, o hospital precisa promover um ambiente Que satisfaça tanto às demandas de cuidado do cliente, Quanto às ações dos profissionais, favorecendo o relacionamento entre estes, contribuindo, assim, com o desempenho adequado de suas funções tendo em vista o cuidado integral ao cliente.

\section{Aspectos implicados nas relações entre clientes e enfermeiras}

$\mathrm{O}$ aspecto psicológico do cliente deve ser foco de atenção da enfermeira antes mesmo de sua chegada no centro cirúrgico, através da visita pré-operatória (VPO). Esta consiste na avaliação do cliente pela enfermeira do centro cirúrgico no período que precede a sua admissão neste setor. Durante a VPO é feita avaliação basal do paciente (avaliação emocional, história anestésica prévia, identificação de alergias, entre outros), momento em Que também se promove a educação em saúde com vistas à preparação do cliente para o ato cirúrgico e recuperação anestésica:

A visita pré-operatória tem um objetivo importante pro paciente: orientar sobre o ato cirúrgico anestésico... A importância daquele procedimento para a recuperação. A gente acredita Que com essa orientação, a gente reduz, também, o estresse do paciente e a ansiedade. (...) Então, a finalidade principal da visita préoperatória é orientar. É informar ao cliente e reduzir, com isso, o estresse, a ansiedade. (...) Quando a pessoa está muito ansiosa... Eu percebo Que está um pouco ansiosa, eu falo: Amanhã a gente se encontra. Amanhã eu estou lá e tal. Não sei o Quê... Eu, às vezes, sei até Que não estarei presente, mas eu já a deixo mais tranqüila. Né? (E6)

Estas visitas devem ter a intenção de além de fornecer as devidas informações e orientações, promover apoio e segurança aos clientes, caracterizando-se como forma de acolhimento e de comunicação entre a enfermeira e o cliente, favorecendo a interação entre esses sujeitos e uma assistência de enfermagem mais individualizada. No entanto, para Que essa interação se efetive, é necessária Que haja autenticidade na relação estabelecida entre enfermeira e cliente. A fala de E6 e as observações Que tivemos a oportunidade de realizar a época da produção de dados desta pesquisa deixam claras Que nem sempre a enfermeira está presente na recepção do cliente por ocasião de sua entrada no centro cirúrgico. Tal fato pode resultar em desgaste emocional ainda maior ao cliente.

Outras vezes, inclusive, esta visita nem ocorre:

Porque ele chega aqui em cima sem saber, às vezes, até o que vai acontecer com ele. Ele sabe Que é uma cirurgia, mas ele não imagina as etapas Que ele vai passar aqui por cima. (E8)

Ao apontar o desconhecimento por parte do cliente sobre o ato cirúrgico-anestésico ao Qual será submetido, E8 evidencia que a VPO ou não é realizada pela enfermeira do Centro Cirúrgico, ou, pelo menos não ocorre de maneira Que o cliente se sinta devidamente esclarecido sobre os seus Questionamentos. Destaca-se que a falta de contato anterior da enfermeira com o cliente pode impedir o acesso às suas expectativas e necessidades e à percepção sobre o seu estado emocional, dificultando o planejamento adequado dos cuidados de enfermagem na sala de recepção pré-operatória, no trans e no pós-operatório imediato.

Apesar de haver vários estudos Que apontam a necessidade da $\mathrm{VPO}^{(16-17)}$, esta não vem sendo uma prática sistematizada nem extensiva a todos os clientes, o Que dificulta uma abordagem mais totalizadora junto a estes. Os referidos estudos vêm destacando o número reduzido de enfermeiros no centro cirúrgico e a sobrecarga de trabalho imposta a esses profissionais como prováveis justificativas para a ausência das VPO. Mas o fato é Que, muitas vezes, o cliente é encaminhado ao centro cirúrgico sem ter recebido de forma plena os cuidados requeridos para o momento.

Ressalta-se que ter conhecimento sobre o procedimento ao Qual será submetido e o poreuê dele ser feito pode contribuir com a redução da ansiedade, insegurança e medo do cliente em relação ao ambiente cirúrgico ${ }^{(17)}$. As especificidades inerentes à situação vivenciada pelo cliente podem lhe gerar além desses sentimentos, preocupações adicionais de diferentes ordens Que podem advir do processo cirúrgico, mesmo Quando não previstas, a exemplo de possíveis incapacidades, tanto do ponto de vista físico Quanto do plano financeiro, ou social. Esses aspectos guardam estreita relação com as condições e circunstâncias nas Quais o processo cirúrgico se dá, se estético ou necessário; se fruto de uma emergência clínica; ou se planejado com o devido tempo. Independente de ocorrer ou não a VPO cabe às enfermeiras da RPO identificar as necessidades dos clientes, com o intento de se trabalhar com os diferentes sentimentos, emoções, inseguranças e Questionamentos Que permeiam esse processo, e Que muitas vezes podem determinar as experiências vivenciadas pelos sujeitos:

Na RPO a gente recebe os pacientes, vê as deficiências. Como o paciente se sente. A aflição dos pacientes... Porque a pessoa sempre vem com ansiedade, né? Então, os pacientes da oftalmologia, são os pacientes Que vêm preocupados com os acompanhantes que estão lá embaixo. (E3)

No pré-operatório, a gente busca a estabilidade emocional dele, diminuir, ao máximo, o risco dele aqui dentro, fazendo uma entrevista bem voltada pra individualidade de cada um. Pra gente descobrir alergias, né! Isso tudo é feito no pré-operatório. (E7)

A entrada do cliente na RPO lhe causa grande impacto e ele pode sentir-se vulnerável, pois deixa "o local conhecido e entra em 
um local desconhecido", sendo, portanto, essencial a presença efetiva da enfermeira nesse momento ${ }^{(9)}$. As expectativas do cliente relacionadas à competência do profissional no Que tange à realização dos cuidados, inerentes a cada fase perioperatória, via de regra, situam-se para além do atendimento às suas necessidades físicas. Ou seja, corresponde também à capacidade da enfermeira de lidar com aspectos Que são da esfera subjetiva do cliente e Que podem interferir no cuidado:

Às vezes, você chega na sala e o paciente... tá, assim, ansioso. Aí, você chega perto. Pergunta... Às vezes, o paciente pergunta pela anestesia. Tem paciente Que... Tem mulher Que deixa filho. Essas coisas. Fica preocupada. (E2)

Em se tratando de um ambiente estranho para o cliente, como é o caso do centro cirúrgico, este pode tornar-se ameaçador, por vezes, hostil, Quando o cliente se depara com uma série de aparatos tecnológicos Que lhes são desconhecidos e distantes de sua realidade de vida. Ademais, vale dizer que as vestimentas dos profissionais, próprias deste ambiente - gorros, máscaras, toucas - também dificultam a efetividade da relação face a face, e podem contribuir para o distanciamento entre cliente e enfermeira. Esses aspectos merecem destaque Quando pensamos em um cuidado congruente e empático, fruto da veracidade das interações e da sintonia necessárias para a valorização e o respeito aos sentimentos do outro e ao seu modo de pensar, agir e se movimentar na vida ${ }^{(18)}$. Para tanto, é importante encontrar meios facilitadores Que promovam a aproximação desses sujeitos.

\section{Relações entre os profissionais de saúde}

A relação interpessoal é um fator Que interfere psicologicamente no profissional. Assim, divergências e discussões entre os profissionais podem acarretar desajustes Que tendem a afetar a dinâmica de funcionamento da unidade, interferindo diretamente no cuidado ao cliente ${ }^{(1)}$. Este aspecto deve ser foco de preocupação da enfermeira no sentido de dirimir seus possíveis efeitos:

$O$ ambiente com o pessoal de enfermagem, com a equipe, eu acho Que é um ambiente bom. (...) Eu não encontro problemas de relacionamento com as equipes, nem com a equipe de enfermagem.(El)

Vindo na contra-mão das experiências positivas de interação presente na fala de EI, a unidade de registro de E9 apesar de pontuar como ideal o bom relacionamento entre profissionais revela Que este nem sempre é possível:

Quando você tem um bom relacionamento com a chefia, com os colegas... Pra mim é o ideal... Você ter um bom relacionamento. Que nem sempre é possível. Mas seria o ideal... Que as pessoas pudessem se relacionar bem. (E I)

Algumas intercorrências, como a falta de material e a sobrecarga de trabalho, podem trazer implicações para o relacionamento entre os profissionais de saúde ${ }^{(2-19)}$ Isto porque a enfermeira responsável pela SO tem como uma de suas atribuições prever e prover recursos materiais para a realização da cirurgia. Quando um determinado material não tem no setor ou o tem em Quantidade insuficiente, esta profissional informa a situação detectada à eQuipe responsável pelo procedimento cirúrgico. Ocorre Que, algumas vezes, o cirurgião responsável mesmo ciente da indisponibilidade do material suficiente no setor embute na enfermeira a responsabilidade pela falta do material na unidade. Estas situações podem implicar em ruídos na comunicação e desajustes no relacionamento interprofissional, afetando a dinâmica de cuidar e de cuidados na unidade ${ }^{(1)}$.

Se você (médico) botou na sala e sabe Que não tem, porQue vai exigir depois? (...) Aí, depois: Chama o enfermeiro._Como se você fosse poder resolver aquele problema, Que ele estava ciente no início. (...) Isso é uma função sua Que você acaba se aborrecendo. (E3)

Devido à disposição da enfermeira da RPO e RPA, presença constante na maior parte do tempo no posto de enfermagem, as atribuições Que são da enfermeira da SO, muitas vezes passam para a enfermeira da RPO/RPA. Quando o cirurgião necessita de algo para a cirurgia e a enfermeira responsável pela SO não está presente em uma determinada sala, em razão de suas atribuições também em outras salas, o cirurgião se encaminha até o posto de enfermagem e faz a solicitação à enfermeira presente neste setor, acarretando, por vezes, prejuízo no estabelecimento das relações:

(...) Muitas coisas Que é da atribuição do enfermeiro do corredor (SO), acaba passando pro enfermeiro da RPO/RPA. Então, tem dia Que a pessoa tá sobrecarregada e fala: "Olha, isso não é comigo. Procura a enfermeira do corredor". Aí, eles (médicos) não Querem. Acham que é má vontade da colega Que não Quer fazer. (E2)

Um relacionamento favorável entre os profissionais atuantes no centro cirúrgico, além de essencial para o bom andamento da cirurgia, também pode promover um ambiente de cuidado harmônico $^{(1)}$. De modo semelhante, é de suma importância a comunicação com o profissional da unidade de internação e de outros setores para Que sejam colhidas informações sobre o cliente: se ele internou ou não, se há alguma intercorrência clínica Que pode acarretar na suspensão da cirurgia, como sinais vitais instáveis, dentre outras. Essas informações colaboram na orientação dos cuidados de enfermagem a serem prestados no centro cirúrgico, proporcionado a continuidade da assistência ao cliente:

Na RPA, a gente se comunica também com os CTI, Que são vários, com a unidade de internação, com o banco de sangue, com os laboratórios. (E7)

Às vezes, você tem Que saber se o paciente foi suspenso. Paciente Que sobe, paciente que desce... CTI; se tem ou se não tem. (E3)

A interação da chefia de serviço com todas as salas de cirurgia, com a RPA, com a chefia de setor e de seção, com a patologia, com o laboratório, com a sala de enfermeiros. (...) Tem Que ter uma interação com tudo isso. (...) É uma interação total.. (E5)

Como se pode denotar, o desenvolvimento do processo de cuidado requer que a enfermeira interaja com esses setores, pois a 
comunicação entre eles é imprescindível para o andamento da cirurgia, a fim de proporcionar uma assistência segura e efetiva ao cliente $^{(1)}$. Enquanto responsável pelo ambiente do Centro Cirúrgico a enfermeira precisa estabelecer um sistema de comunicação mútuo entre as pessoas Que atuam neste espaço, fortalecendo o desempenho e desenvolvimento destes profissionais baseado na cooperação de um trabalho em equipe. Assim, cabe à enfermeira, não somente zelar pelos recursos materiais, mas também pelas relações interpessoais neste ambiente, uma vez que estas interferem positivamente na prestação dos cuidados de enfermagem ao cliente:

Elas [enfermeiras] têm Que trabalhar em conjunto. Eu tenho as minhas salas, mas eu tenho Que estar inteirada nas salas das colegas. (E2)

É oportuno ressaltar Que este ambiente de cooperação mútua relaciona-se, muitas vezes, à satisfação profissional. Algumas enfermeiras participantes deste estudo apontaram este aspecto como favorecedor à sua atuação no centro cirúrgico, incluindo o cuidado direto ao cliente:

(...) A vontade de trabalhar. Você gostar do Que você faz... Então, a gente faz com amor, carinho... Com vontade de acertar. Então, tudo isso é um fator Que favorece muito. (E5)

Agora, o seu trabalho independe se tem muito ou pouco (recursos materiais e humanos). Se você gosta, você vai fazer com boa vontade. (E8)

Vale ter em consideração Que mesmo diante de condições numericamente insatisfatórias de profissionais, tal fato não deve ser visto como impeditivo para Que um cuidado de Qualidade seja desenvolvido, embora possa nele, interferir. Como foi possível analisar a partir dos resultados oriundos das técnicas utilizadas na produção de dados, não obstante as dificuldades apresentadas de diferentes ordens no centro cirúrgico e Que interferem nos cuidados de enfermagem, imprimir Qualidades humanas no cuidado, como demonstração de afeto e carinho, aliadas à dedicação, à satisfação no trabalho e à interação entre os profissisonais, são aspectos Que podem contribuir com o desenvolvimento do cuidado, no atendimento às necessidades e desejos manifestados pelo cliente cirúrgico.

\section{CONSIDERAÇÕES FINAIS}

O cuidado com o ser humano deve ser direcionado como um todo - biológico, social, psicológico e espiritual - enfatizando a necessidade de comunicação e atenção, valorizando as experiências individuais, os valores sociais e humanos, emoções, desejos, e todo o contexto necessário para o entendimento do sujeito. O cuidado de enfermagem mais especialmente visa à promoção da saúde, preservação e proteção da vida, promoção do conforto e bemestar do homem. Implica em uma intervenção tanto direta ao cliente, Quanto em ações Que são desenvolvidas em prol de sua plena restauração, incluindo o ambiente Que o integra, de modo a manterse harmônico e equilibrado.

Destarte, a enfermeira preocupa-se com a organização e com o tempo Que dispõe para o desenvolvimento de suas ações, com a provisão e previsão do material instrumental e humano, com o ambiente físico e de relações interpessoais autênticas e recíprocas, tendo como foco principal o cuidado ao cliente. Ou seja, as observações e intervenções da enfermeira são no sentido de manter o ambiente em condições favoráveis ao desenvolvimento do cuidado de modo a torná-lo promotor de saúde/cuidados.

\section{REFERÊNCIAS}

1. Stumm EMF. Dificuldades enfrentadas por enfermeiros em um Centro Cirúrgico. Texto Contexto Enferm 2006; 15 (3): 464-71.

2. Spíndola T. O exercício profissional dos enfermeiros no contexto dos hospitais universitários. Esc Anna Nery Rev Enferm 2003; 7(3): 325-33

3. Rossi FR, Silva MAD. Fundamentos para processos gerenciais na prática do cuidado. Rev Esc Enferm USP 2005; 39 (4): 460-8.

4. Nightingale F. Notas sobre enfermagem: o Que é e o Que não é. São Paulo: Cortez; 1989.

5. Monteiro VO. A imagem do álcool na vida dos adolescentes: sua relação com a prática educativa-dialógica da enfermeira [dissertação]. Rio de Janeiro: Escola de Enfermagem Anna Nery, Universidade Federal do Rio de Janeiro; 1999.

6. Bardin L. Análise de conteúdo. Lisboa: Edições 70; 2004.

7. Ministério da Saúde (BR). Agência Nacional de Vigilância Sanitária: Resolução RDC n50/2002. Dispõe sobre normas destinadas ao exame e aprovação dos projetos físicos de estabelecimentos assistenciais de saúde. Brasília (DF); 2002. [citado em 28 de julho de 2008]. Disponível em: URL: http:// www.anvisa.gov.br.

8. Association of Perioperative Registered Nurses (AORN).

Standards recommended practices and guidelines. Denver (CO) AORN; 2004

9. Bianchi ERF, Turrini RNT. Planejamento físico do centro cirúrgico. In: Bianchi ERF, Carvalho R, organizadores. Enfermagem em centro cirúrgico e recuperação. I ${ }^{\mathrm{a} e d}$. Barueri: Manole; 2007. p. 22-37.

10. Figueiredo NMA, Santos I. Introduzindo a enfermagem clínica no ambiente terapêutico hospitalar. In: Santos I, Figueiredo NMA, Padilha MICS, Cupello AJ, Souza SROS, Machado WCA. Enfermagem assistencial no ambiente hospitalar: realidade, Questões, soluções. São Paulo: Atheneu; 2005. p. 3-20.

11. Fraga FC. A implantação do Hospital Universitário da UFR] (1974-1978). Rio de Janeiro: Fundação Universitária José Bonifácio; 1990.

12. Sociedade Brasileira de Enfermeiros de Centro Cirúrgico, Recuperação Anestésica e Centro de Material e Esterilização (SOBECC). Práticas recomendadas da SOBECC. $4^{\mathrm{a} e d}$. São Paulo: SOBECC; 2007.

13. Waldow I. Cuidado Humano: o resgate necessário. $2^{\mathrm{a}}$ ed. Porto Alegre: Sagra Luzzato; 1999.

14. Araújo STC, Silva MVG, Santoro DC, Porto ISS. Intervenções de enfermagem em perioperatório. In: Santos I, Figueiredo 
Silva DC, Alvim NAT.

NMA, Padilha MICS, Cupello AJ, Souza SROS, Machado WCA. Enfermagem assistencial no ambiente hospitalar: realidade, Questões, soluções. São Paulo: Atheneu; 2005. p. 209-26.

15. Moura ACF. A unidade de Quimioterapia na perspectiva dos clientes: indicativos para o enfermeiro na gestão do ambiente [dissertação]. Rio de Janeiro: Escola de Enfermagem Anna Nery, Universidade Federal do Rio de Janeiro; 2005.

16. Pellizzetti N, Bianchi ERF. Visita pré-operatória de enfermagem: análise retrospectiva. Rev SOBECC 1999; 4 (I): 24-8.
17. Feu RMS, Maciel AA. A visita sistematizada de enfermagem pré e pós-operatória no atendimento das necessidades do paciente. Rev SOBECC 2008; 13 (2): 24-3I.

18. Talento BJW. In: George JB et al. Teorias de Enfermagem: os fundamentos para a prática profissional. $4^{\mathrm{a}}$ ed. Porto Alegre: Artes Médicas Sul; 2000.

19. Silva BMS. Jornada de trabalho: fator que interfere na Qualidade da assistência de enfermagem. Texto Contexto Enferm 2006; 15(3): 442-8. 